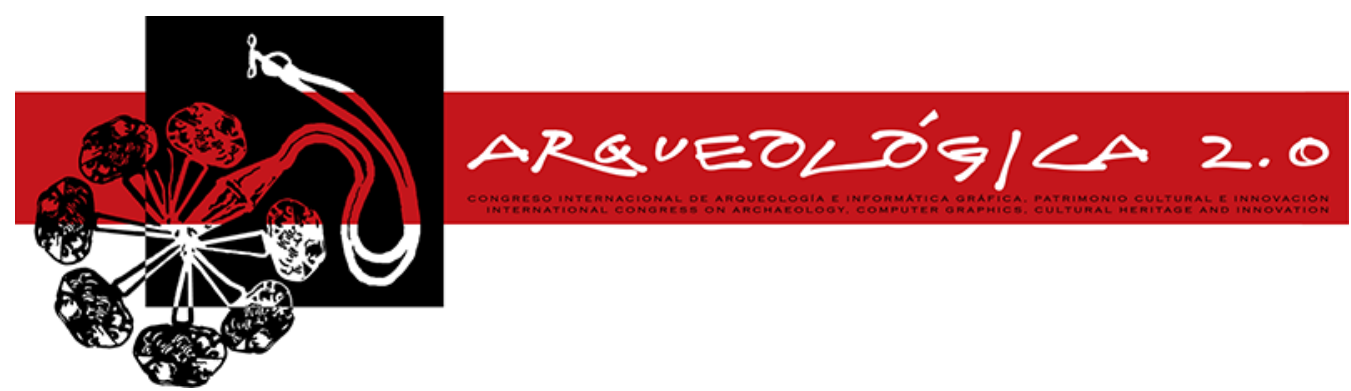

Proceedings of the $8^{\text {th }}$ International Congress

on Archaeology,

Computer Graphics,

Cultural Heritage and Innovation

'ARQUEOLÓGICA 2.0'

in Valencia (Spain),

Sept. $5-7,2016$

DOI: http://dx.doi.org/10.4995/arqueologica8.2016.3998

\title{
LA APLICACIÓN DE NUEVAS TECNOLOGÍAS EN LA DOCUMENTACIÓN ARQUEOLÓGICA DE LA VILLA ROMANA DE NOHEDA Y SU PROYECCIÓN TURÍSTICA DIGITAL
}

\section{THE APPLICATION OF NEW TECHNOLOGIES IN ARCHAEOLOGICAL DOCUMENTATION ABOUT THE ROMAN VILLA OF NOHEDA ITS TOURIST DIGITAL PROJECTION}

\author{
Miguel Ángel Valero ${ }^{\mathrm{a},{ }^{*}}$, Nuria Huete ${ }^{\mathrm{b}}$ \\ ${ }^{a}$ Centro Asociado de la Universidad Nacional de Educación a Distancia en Cuenca, Colón 6, 16002 Cuenca, España. \\ mvalero@cuenca.uned.es \\ ${ }^{\mathrm{b}}$ Departamento Economía Española e Internacional, Econometría, Historia e Instituciones Económicas. Facultad de Ciencias \\ Económicas y Empresariales de Albacete, Universidad de Castilla-La Mancha, Plaza de la Universidad 1, 02071 Albacete, España. \\ Nuria.Huete@uclm.es
}

\begin{abstract}
:
The Roman villa of Noheda has become one of the crucial site to understand the messages that the high Roman aristocracy intended to convey by the building infrastructure in these large rural complex of Late Antiquity. Therefore, for the application of a correct archaeological methodology we should add the use of the most modern techniques of research and analysis that were within our grasp, in order to document in the best possible detail, the archaeological remains. Understanding that only through a close reading we can get to properly decrypt the data housed in the cluster of structures and artifacts hosted in the stratigraphic sequence. Therefore, the aim of this article is to present concisely, how technological advances have been used such as ground penetrating radar, 3D scanning, laser scanner, photogrammetry, etc. and the best results which have been obtained. In the same way, we will explain that these results are just a first step, because today the project of musealisation of the site has begun in order to be ready for its opening to the public and, within the innovations that bring the new technologies will be taken into account and they will be used in situ with mobile telephony, such as 3D modeling of parts and its Georeferencing, the increased virtual reality, etc. Nonetheless we must not forget other advances which help understand, spread and bring archeology closer to society.
\end{abstract}

Key words: roman villa, triclinium, photogrammetry, three-dimensional scanning, georradar, virtual reality.

\section{Resumen:}

La villa romana de Noheda se ha convertido en uno de los yacimientos cruciales para entender los mensajes que la alta aristocracia romana pretendía transmitir mediante la edilicia en estos grandes complejos rurales de la Antigüedad Tardía. Por ello, a la aplicación de una correcta metodología arqueológica debía sumarse el uso de las más modernas técnicas de investigación y análisis que estaban a nuestro alcance, con el fin de poder documentar con el mayor detalle posible los restos arqueológicos. Entendiendo que solo mediante una lectura minuciosa se puede llegar a descifrar adecuadamente los datos albergados en el cúmulo de estructuras y artefactos insertos en la secuencia estratigráfica. Por ello, el objetivo de este artículo es exponer de manera concisa, cómo se han utilizado avances tecnológicos como el georradar, escaneado 3D, láser escáner, fotogrametría, etc. y los óptimos resultados que se han obtenido. Del mismo modo, se explicará que estos resultados no son sino un primer paso, pues a día de hoy se ha comenzado con el proyecto de musealización del yacimiento de cara a su apertura al público y en él se tendrán muy presentes las novedades que aportan las nuevas tecnologías que puedan ser usadas in situ con la telefonía móvil, como el modelado 3D de piezas y su georreferenciación, la realidad virtual aumentada, etc. Pero sin olvidar otros avances que ayuden a comprender, difundir y socializar la arqueología.

Palabras clave: villa romana, triclinium, fotogrametría, escaneado tridimensional, georradar, realidad virtual.

*Corresponding Author: Miguel Ángel Valero, mvalero@cuenca.uned.es 


\section{Introducción}

La presente contribución supone la presentación de cómo se han aplicado algunas de las más novedosas técnicas de documentación en el proyecto de investigación que estamos efectuando en la villa romana de Noheda. Con el empleo de las mismas se busca un objetivo primordial, el registro exhaustivo de todos los datos obtenidos en el proceso de excavación del yacimiento, entendiendo a ésta como la única manera de plasmar de forma rigurosa la información exhumada, que posteriormente ayudará a la recostrucción no solo del inmueble, sino también del entorno del mismo y del mensaje que el dominus quería transmitir a los visitantes del complejo.

Este trabajo surge de la necesidad de contribuir al estudio integral del yacimiento, ya que, si bien es justo reconocer que hasta el momento ha sido mosaico figurado localizado en el triclinium de la villa la evidencia más notoria del mismo por la cual es conocido (Valero 2009; 2010; 2011; 2013a; 2014b; 2014c; 2015a; 2015b; Valero y Gómez 2013). Consideramos que la investigación sobre el enclave debe plantearse de manera integral, es decir, sin olvidar el tapiz musivario, pero otorgando la misma relevancia al resto de los aspectos conformadores del complejo. En esta línea, y aplicando algunas de las técnicas que más adelante detallaremos, ya se han efectuado algunos estudios analizando arquitectónicamente diversas estancias, la cronológica del complejo, la evolución de las fases constructivas, la edilicia empleada y el proceso de destrucción (Valero 2014a). Del mismo modo, también se han abordado análisis sobre los elementos que ornamentaban la pars urbana del conjunto (Valero et al. 2015), el estudio de captación de recursos hídricos con los que se abastecía el complejo rural (Mejías et al. 2013; Martínez et al. 2014), o los primeros resultados sobre los programas de prevención y conservación efectuados en el tapiz musivario (Valero et al., 2014). Además también se ha realizado el analisis del territorio susceptible de conformar el fundus de la quinta, y sus adaptaciones y/o transformaciones con motivo de la inserción de este espacio, en el ámbito de explotación de la villa (Valero e.p.).

\section{El yacimiento}

La existencia del yacimiento de la villa romana de Noheda y de mosaicos en el mismo, es conocido desde antiguo (Larrañaga 1966; Abascal 1982; Palomero 1987), si bien la constancia del tapiz figurado fue documentada en los años 80 del siglo pasado como consecuenca de la realización de unos trabajos de mejora agrícola que se estaban efectuando en la parcela (Lledó 2007, 2010).

Pero es tan solo en fechas recientes cuando ha comenzado a ser difundido de manera rigurosa, (Valero 2009; 2010; 2011; 2013a; 2014a; 2014b; 2014c; 2015b; Valero y Gómez 2013; Valero et al. 2014; Valero et al. 2015).

El enclave se ubica en la parte central de la Península Ibérica, próxima de las ciudades de Segóbriga (a 58 $\mathrm{km}$ ), Ercávica (a 44,5 km) y Valeria (a 43,5 km), situándose a $17 \mathrm{~km}$. al norte de la ciudad de Cuenca. La villa se localiza a escasos $500 \mathrm{~m}$ al noroeste de la localidad de la cual toma su nombre, siendo ésta pedanía del municipio de Villar de Domingo García (Fig. 1).

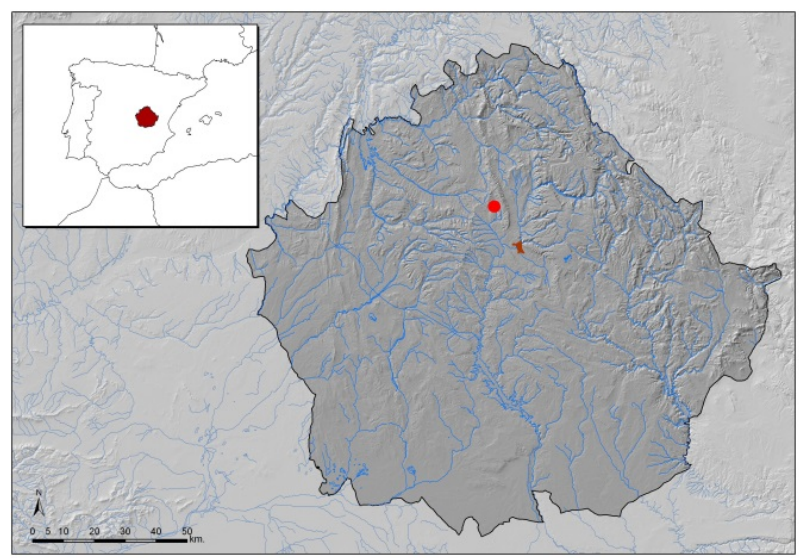

Figura 1: Plano de localización de Noheda en el contexto peninsular.

El complejo arqueológico fue declarado Bien de Interés Cultural en 2012, principalmente por los mosaicos descubiertos en él, si bien no es solo la etapa tardoantigua la que cuenta con evidencias antrópicas, aunque es justo reconocer que es hasta el momento, la mejor documentada. Las investigaciones realizadas en los últimos años han puesto de manifiesto que bajo la villa tardorromana, resulta probada la existencia de estructuras arqueológicas pertenecientes al Alto Imperio, en un estado de conservación aceptable pese a haber sido cantera de las construcciones suprapuestas. Éstas últimas coinciden cronológicamente con el proceso de eclosión y auge de las grandes villae documentadas en la parte occidental de Imperio (Vera 1992-1993; Volpe 1996; Sfameni 2006; Chavarría 2006; 2007; Pensabene 2010-2011; Hidalgo, 2014).

Además los análisis territoriales efectuados en su entorno inmediato (Valero 2013b), denotan una intensa actividad humana en estas tierras, evidenciando poblamiento desde época protohistórica hasta la alta Edad Media de manera ininterrumpida.

Su ubicación geográfica en el contexto peninsular, determina un marcado carácter de cruce de caminos, convirtiéndose en un paso natural de sur a norte entre las cordilleras montañosas que la rodean, haciendo de esta zona una vía natural de comunicación (Valero 1999a; 1999b; 2008) que precisamente recorren algunas calzadas romanas (Abascal 1982; Palomero 1987; Valero 2013b).

Hasta el momento son tres las áreas exhumadas del complejo rural. Por un lado, algunas estructuras pertenecientes a la pars rustica que con su sola presencia, implica que el complejo contaría con los edificios necesarios que le otorgarían esa vocación agrícola que resulta inherente al concepto de villa rústica (Richmond 1970; McKay 1975; Percival 1976; Johnston 1983; Balmelle 2001; Gros 2001; Mulvin 2002; Chavarría 2005; 2007; Arce 2006; 2009; 2012; Sfameni 2006).

Por otro lado, y habiendo centrado los esfuerzos en estas zonas, se ha excavado una parte de la pars urbana, compuestas por el balneum y determinadas estancias del sector residencial. Por lo que respecta al 
primer edificio, disfruta de unas dimensiones de casi 900 $\mathrm{m}^{2}$ y cuenta con esquema axial-simétrico (García-Entero 2005; 2006). Está compuesto por diversas salas de uso, -a los que hay que sumar varios praefurnia- dispuestos en torno al eje central que marcan la entrada en narthex, el apodyterium y el gran frigidarium. Tal y como se manifiesta en otros recintos termales fechados a partir de finales del siglo III o a lo largo del siglo IV , en Noheda se aprecia el gusto por la complejización de los esquemas de funcionamiento y la profusión de espacios absidados $\mathrm{u}$ octogonales.

A la monumentalización arquitectónica del balneum, se le suma la preeminencia de las salas de ambiente frío, que no solo ocupan la mayor parte del edificio, sino que disfrutan de un recargado aparato ornamental compuesto por un vistoso pavimento de mosaico -del cual solo quedan algunas evidencias- y un colorido zócalo en los paramentos murados que se resuelve mediante opus sectile en alternancia de tonos y tipos gran parte de los mismos importados de casi todo el ámbito mediterráneo- que pone de manifiesto el empleo de materiales constructivos nobles en la decoración de las estancias principales de la villa, pudiendo ser asociados al gusto de la élite social que tal y como han apuntado otros (Rodà 2004), promociona el surgimiento de talleres locales e itinerantes dedicados a ejecutar complejos y caros programas decorativos

Por lo que respecta a las estructuras de uso residencial, hasta el momento han sido siete las estancias completamente excavadas, pero entre ellas destaca la denominada Sala Octogonal y la Sala Triabsidada (Fig. 2) que disfruta de unas imponentes dimensiones -de 290,64 $\mathrm{m}^{2}-$, y de unos extraordinarios pavimentos, a lo que ha hay que sumar una compleja articulación arquitectónica y una cuidada decoración parietal compuesta por un zócalo de placas de mármol y un alzado de pintura mural. Su morfología cuadrangular con exedras en tres de sus lados, permiten adscribirla al tipo de salas tríforas que se hacen frecuentes en los más lujosos conjuntos residenciales datados a partir de finales del siglo III (Romizzi 2006). Se trata de dependencias de articulación trichora que se interpretan como triclinia (Hidalgo 1998; 2014; Dunbabin 2003; Mar y Verde 2008; Arce 2010), adaptando así las formas arquitectónicas a las nuevas tendencias en la organización espacial de los comensales de banquetes, con lechos dispuestos en semicírculo, los stibadia (Rossiter 1991; Volpe 2006).

Es en esta estancia donde se halla un excepcional mosaico con unas dimensiones conservadas de 231,62 $\mathrm{m}^{2}$, realizado en su mayor parte con opus vermiculatum de una variadísima gama cromática, utilizándose para determinados colores piezas de pasta vítrea en multitud de tonos e incluso doradas.

La composición ornamental de este pavimento está formada por un lado, de una amplia zona central dividida en seis paneles con escenas de temática mitológica y alegórica, que presentan un carácter unitario y donde se abigarran profusamente las figuras, aglutinándose en grupos escénicos. Este conjunto figurativo, cuya forma rectangular se reparte el espacio principal de la sala, se extiende entre el centrado estanque monumental y el enmarque realizado con una amplia orla vegetal de roleos de hojas de acanto, más elaborados en la parte central de las tiras, en los espacios coincidentes con el acceso a las tres exedras de la estancia, que contarían con decoración geométrica, a tenor de lo observado en las dos conservadas.

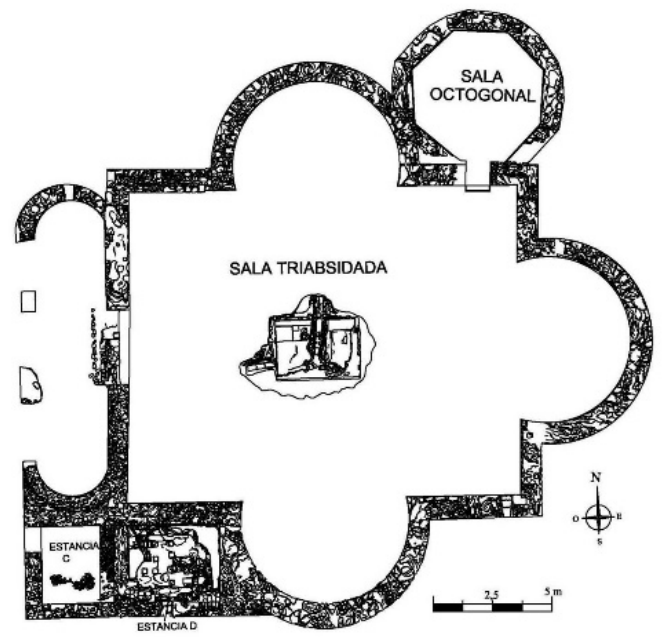

Figura 2: Planimetría de las principales estancias del sector residencial hasta ahora excavadas.

Los cuadros figurativos fueron estructurados en seis franjas rectangulares, denominadas, a efectos de descripción y estudio, por orden de visionado del visitante a la sala: $A, B, C, D, E$ y $F$ (Fig. 3).

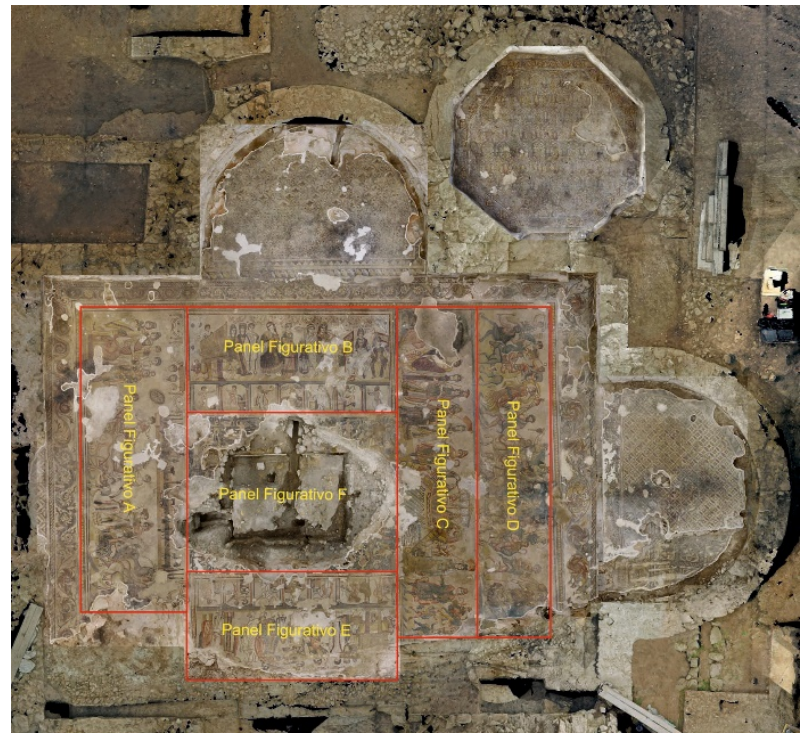

Figura 3: Indicación de las bandas figurativas del mosaico. Foto J. Latova.

Así el Panel Figurativo A representa la contienda mantenida entre el rey de Olimpia, Enómao y el príncipe anatolio, Pélope por Hipodamia, la hija de aquel. Se divide en tres grupos escénicos, el primero de ellos compacto, de cinco personajes en torno al monarca entronizado, el siguiente refleja en primer lugar, el violento naufragium sufrido por la cuadriga del soberano, continuando con la plasmación de Pélope vencedor descendiendo de la barquilla del carro mientras es abrazado por Hipodamia y recibe de ésta la palma de la victoria. Completaría la escena un tercer conjunto del que solo quedan dos personajes que asisten a los corceles, habiendo sido destruido por la 
acción del arado. Sobre el cuadro escénico principal, otro ubicado en la parte superior de menores dimensiones en la que se aprecia un circo -alusivo a la carrera de cuadrigas- donde se plasma la cavea, la arena, la spina, las metae, los ovaria, el phala, así como varias esculturas de dioses $y$ animales que ornamentarían el edificio.

El Panel Figurativo B, ubicado en la zona norte de la sala se divide igualmente en dos subescenas, en la principal, representa una compañía teatral en la que se suceden todos los componentes de la pantomima, bajo ésta se sitúa otra de menores dimensiones cuyos personajes, alusivos a los ludi, se encuentran enmarcados entre dobles columnas techadas por una sucesión de dinteles rectos y arcos escarzanos

El Panel Figurativo C se localiza en la parte oriental de la estancia, dividiéndose igualmente en grupos escénicos. El primero de ellos compuesto por un conjunto de cinco personajes, tres femeninos frente a uno masculino vestido con túnica y sentado sobre una roca a la sombra de un árbol, entre ellos Eros. Representa el juicio de Paris. El siguiente conjunto escénico, se desarrolla en torno a un barco con cuatro marineros a bordo, dos de ellos que se afanan en izar las velas y desatracar la nave, mientras los otros dos tripulantes centran sus esfuerzos en atar amarras, simbolizando unos la partida y otros la llegada a puerto. Al navío, mediante una rampa situada en la popa, accede Paris mientras agarra la mano de la raptada Helena que va acompañada de tres asistentas, que portan respectivamente, una sombrilla, un espejo y un cofre. Al otro lado de la nave, por la proa, los mismos cinco personajes descienden por la pasarela, para ser recibidos por dos parejas de danzantes con indumentaria frigia, ante una construcción amurallada identificable con Troya.

El Panel Figurativo D, está ubicada igualmente en ese lado oriental de la sala. En él se plasma un cortejo dionisiaco en el que el dios representado como un joven de largos cabellos, aparece subido en una cuadriga tirada cubierta por un pardalis, y tirada por cuatro centauros músicos que tocan el aulos y la siringa. El carro es antecedido por el resto de personajes asociados a este thiasos: ménades, sátiros, el dios Pan, Sileno y animales de filiación oriental.

El Panel Figurativo E, localizado y orientado hacia la parte meridional de la sala es muy similar al panel B arriba mencionado, apreciándose solamente ligeras variaciones en la posición y dinamismo de las figuras, así como en el cambio de orientación de determinados personajes. Como en el caso antes analizado, las escenas menores son alusivas a ludi.

Por último, el Panel Figurativo $\mathrm{F}$ parcialmente destruido por la caída de la cúpula de la estancia, representa diversos motivos marinos, -escenas de pesca, erotes, tritones y nereidas-, acordes con la naturaleza acuática del estanque que enmarcaban.

Sumado a la ornamentación estructural, se han documentado una gran cantidad de fragmentos escultóricos, que al igual que en otros casos (Rodà 2004), apuntan a la posibilidad de que los propietarios de la villa pertenezcan a la más alta clase social, con capacidad para importar excepcionales piezas de la Península Itálica y de la parte oriental del Mediterráneo.

\section{Aplicación de nuevas tecnologías al método arqueológico usado en Noheda}

La metodología y las técnicas de excavación arqueológica se han ido depurando y normalizando en las últimas décadas. De hecho, en Noheda se han aplicado las últimas novedades, empezando por obviar el obsoleto método arqueológico basado en la apertura de pequeñas cuadrículas en retícula, para pasar a la excavación en área abierta que permite documentar sin interrupciones artificiales, toda la secuencia estratigráfica.

En concordancia con la adopción de las últimas tendencias en metodología y las técnicas de excavación arqueológica en el yacimiento, se ha optado por la aplicación de algunos de los más novedosos avances tecnológicos de cara a la obtención de una documentación rigurosa que permita, por un lado el adecuado registro de la ingente información extraída en el proceso excavado, y por otro, obtener un excepcional banco de datos que admita continuar usando y "explotando" las nuevas tecnologías de cara a la museización y difusión del enclave.

Como se podrá comprobar en las páginas sucesivas, el equipo científico responsable de las investigaciones en Noheda, ha estado muy atento a los avances tecnológicos, siendo siempre unos de los primeros yacimientos en aplicar las más novedosas técnicas conforme se posibilitaba su uso en el mundo de la arqueología.

\subsection{Fotogrametría aplicada a la planimetría}

En la actualidad, algunas de las técnicas empleadas en la arqueología han evolucionado de manera exponencial con la llegada de la era digital. Dos de las más destacadas han sido la fotografía y la topografía.

Los últimos años ha supuesto un salto cualitativo en las técnicas de registro topográfico con la llegada de estaciones totales robotizadas, GPS diferenciales, láser escáner, etc. Además la evolución de registro fotográfico ha tenido un crecimiento fulgurante, permitiendo tanto el aumento de la calidad de las imágenes, como las posibilidades de edición y presentación.

La fusión de ambas vertientes es la fotogrametría, que adquiere unas destacadas posibilidades para la documentación del registro arqueológico, pero también para la ulterior puesta en valor del yacimiento.

De este modo, la fotogrametría es una disciplina que une las matemáticas, la fotografía y la óptica para determinar las propiedades geométricas de los objetos fotografiados a través de solapamiento de fotografías, basadas en principios trigonométricos.

Atrás quedaron los costosos programas y los potentes computadores necesarios para generar los cálculos matemáticos aplicados para obtener la orientación del modelo. En la actualidad diversos programas - muy asequibles, incluso gratuitos- se encargan de manera casi automática de todo el procesado y sin necesidad de contar con maquinarias específicas, solo con una cámara de fotos de buena calidad y un ordenador (Westoby et al. 2012). 
En nuestro caso, se han empleado aplicaciones de software libre, concretamete Visual SfM que cuenta con reconocida eficiencia de cara a la obtención de modelos fotogramétricos aplicables a 3D (Wu 2013; Shan et al. 2014). Además las ortoimágenes se han tratado con un programa específico de reconocida eficiencia en otros proyectos (Jancosek y Pajdla 2011).

De este modo, los resultados obtenidos en Noheda han tenido gran éxito, sumándose a un grupo de yacimientos que los emplean de manera satisfactoria (Doneus et al. 2011; De Reu et al. 2013; McCrarthy 2014).

Desde que el equipo científico tuvo acceso a este tipo de tecnología, en 2012, las secuencias estratigráficas de interés, así como diversos ítems destacados que resultan cruciales para el entendimiento del contexto arqueológico, han sido documentados mediante esta técnica (Fig. 4). Con ello, se deja constancia con coordenadas absolutas y un error métrico de como mucho $3 \mathrm{~mm}$, de toda la información extraída de la tierra. Ésto permite - si fuese necesario-, "reexcavar" ya en el laboratorio cualquier sedimento, quedando así abierta la posibilidad a ulteriores revisiones que pueden venir motivadas por diversos hallazgos conforme se vaya avanzando en la excavación.

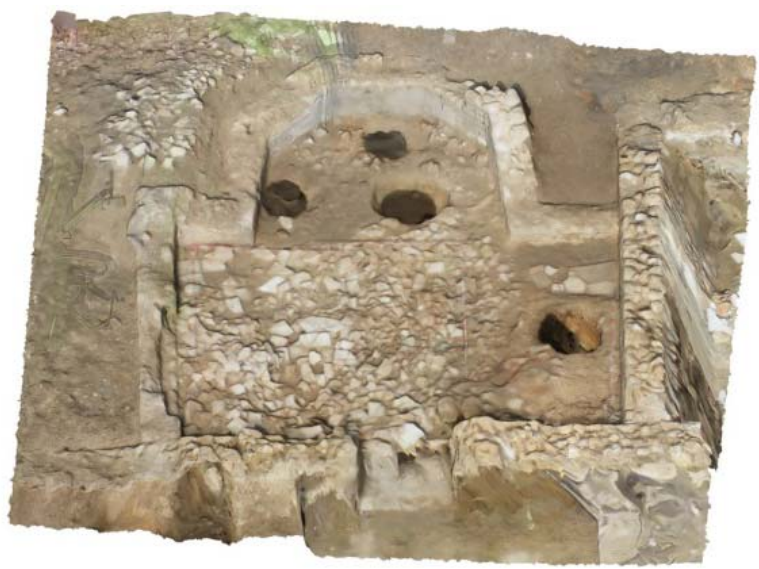

Figura 4: Proyección fotogramétrica del uctorium de la balneum en en proceso de excaación de la UE 34

Con ello, se ha documentado con gran precisión todos los restos arqueológicos, permitiendo que la ingente cantidad de datos obtenidos, sea convenientemente tratada, con un bajo coste y grandes posibilidades de gestión digital de los resultados. Esto permite desde la integración a un GIS, hasta la generación de archivos básicos para la reconstrucción completa del yacimiento (Bezzi 2013).

\subsection{Aerofotogrametría con drone}

De manera paralela al desarrollo fotogramétrico aplicado en el yacimiento, desde 2015 se optó por la combinación de esta técnica con otra de reconocida eficiencia en yacimientos de grandes dimensiones, como es fotografía por drone (Poirier et al. 2014).

Esta tecnología aérea también ha experimentado una evolución importante en los últimos años, dejando atrás los caros y pesados drones dotados con motores de gasolina. En la actualidad se ha pasado modelos eléctricos dotados de estabilizadores, brújula digital,
GPS, control remoto por ordenador y planificación de rutas (Ruiz et al. 2015) y lo más importante, precios muy competitivos que ha permitido su empleo en proyectos como el nuestro.

En primer lugar se fijaron los puntos de referencia para la triangulación de la parcela objeto de estudio, en nuestro caso los vértices geodésicos más cercanos al yacimiento.

Posteriormente, a la hora de programar el vuelo aerofotogramétrico, el itinerario a realizar por el drone de cara a la obtención de las tomas generales georreferenciadas de la excavación no se ejecutó de manera manual ya que podría dar lugar a cierta subjetividad a la hora de incidir en la documentación de determinadas zonas en detrimento de otras. Por ello, de acuerdo a la meticulosa metodología aplicada, se planificó previamente la ruta del aparato en el ordenador con un programa específico (Fig 5).

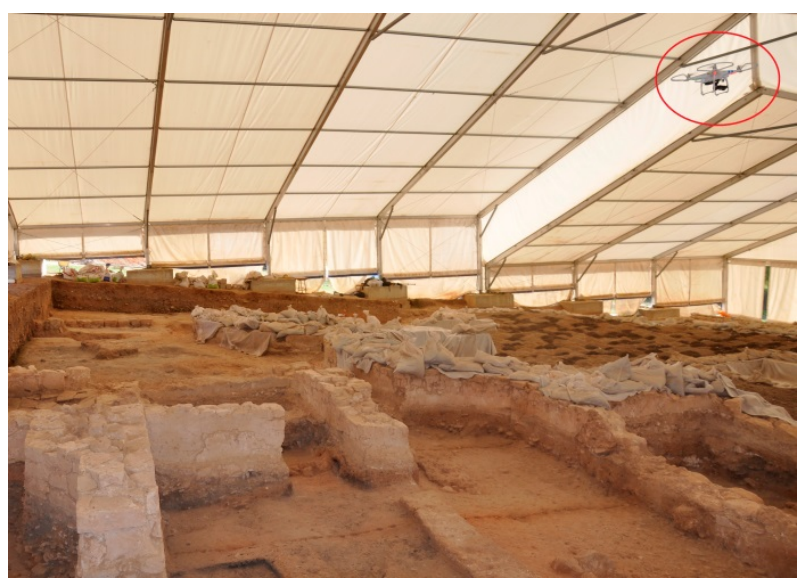

Figura 5: Vuelo del drone sobre los restos del sector residencial de la villa de Noheda.

Las imágenes tomadas en el vuelo se efectuaron con una cámara Nikon D 7100 con sensor de imagen CMOS de formato DX y 24.1 megapíxeles, con un rango focal f2-5.9, una velocidad máxima de obturación de 1/2000 y una distancia focal de $24 \mathrm{~mm}$. Se instaló un programa adicional (CHDK) para actualizar el firmware de cara a la generación de fotografías a intervalos. Del mismo modo, también se han realizado fotos con una cámara GoPro Hero3+, con una apertura del diafragma de f2.8 fija y equipada con una óptica potente con un gran angular. Las imágenes fueron realizadas tanto en JPG como en RAW para exprimir más los datos fotográficos.

Ambas cámaras se programaron para realizar fotografías cada segundo. De este modo se consigue que las imágenes obtenidas se solapen al menos en un $60 \%$, por lo que si alguna fotografía está defectuosa podría ser eliminada con total tranquilidad, sin afectar al conjunto del proyecto.

Una vez comprobadas las imágenes, se pasa al trabajo de laboratorio que se desarrolla con los mismos programas ya indicados en el apartado anterior.

\subsection{Escaneado 3D de triclinium y sus mosaicos}

Como se apuntó anteriormente, uno de los elementos más destacados del yacimiento es su impresionante 
mosaico figurativo. Del mismo, resalta la gran calidad técnica conseguida a la hora de ejecutarlo, por lo que parece una obra pictórica más que musivaria.

Se trata por tanto de pavimento realizado en su mayor parte de opus vermiculatum, con teselas milimétricas algunas de ellas de $1,5 \mathrm{~mm}$ - de una variadísima gama cromática, utilizándose para determinados tonos piezas de pasta vítrea e incluso doradas. Se consiguen así infinidad de matices, destacando el cuidado estudio anatómico del cuerpo humano, el dinamismo de las figuras en movimiento y la expresividad de los personajes. A todo esto se suma, el excelente estado de conservación, habiendo perdido, sólo una pequeña parte de su superficie, que en modo alguno afecta a la interpretación global de las escenas.

Esta excepcionalidad, hacía necesario una documentación acorde a su relevancia, aplicando un método de medición no intrusivo que permitiera una captura de información rápida, detallada y precisa de una superficie por medio de una herramienta basada en la tecnología de escáner con láser.

Por ello, en 2009 se optó por efectuar un escaneado 3D, mediante un láser escáner tipo FARO LS 880 3D (Fig. 6 ), que permite generar gran cantidad de mediciones tomadas de manera rápida y muy precisa. Dimensiona hasta 140.000 puntos por segundo, siendo necesarios solamente 4 minutos para realizar los $360^{\circ}$.

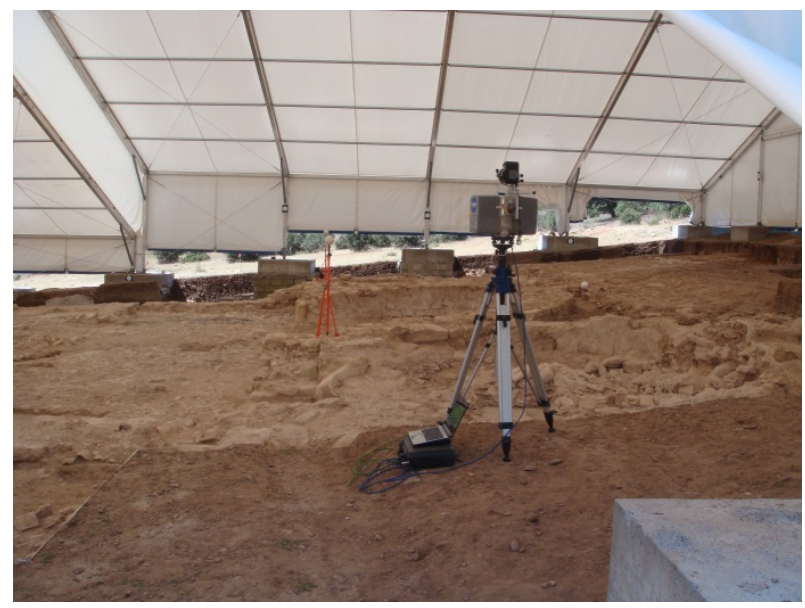

Figura 6: Toma de datos del mosaico mediante láser escáner.

Como en otros casos de características parecidas (Mañana-Borrazás et al. 2008), al ser un sistema que documenta una superficie por medio de láser, se tuvo que combinar distintas posiciones del escáner ya que la existencia de muros de hasta $1,20 \mathrm{~m}$ de altura conservada, impedia el registro de algunas partes de otros elementos que permanecían ocultas desde la posición de la máquina, generando zonas de sombra en la nube de puntos.

Posteriormente, el conjunto de escaneos fueron combinados en un registro único gracias a las dianas de control que sirven como referencia.

El resultado final fue la obtención de una nube de puntos 3D compuesta por cientos de miles de mediciones individuales en un sistema de coordenadas $(\mathrm{x}, \mathrm{y}, \mathrm{z})$, que en sí mismas componían un modelo tridimensional del triclinium de Noheda y sus mosaicos.
Paralelamente se realizaron las pertinentes fotografías con cámaras dotadas de objetivo de alta gama, a lo que se suma un respaldo digital que permitió obtener ficheros con al menos 60 megas. De esta manera, las imágenes georreferenciadas reflejaban todas las teselas y las juntas existentes entre ellas. Esta documentación sirvió para ulteriores investigaciones efectuadas sobre el tapiz musivo.

En la actualidad, se cuenta con la posibilidad de realización de otra campaña de escaneado 3D del triclinium de Noheda y sus mosaicos con una maquinaria más avanzada, acorde a las fechas actuales, concretamente un modelo Faro Focus ${ }^{3 \mathrm{D}}$ X130. La nube de puntos obtenidos en la primera lectura, es de gran valor y será cotejada con la resultante a efectuar. Con ello, se dispondrá de un completísimo mapeado milimétrico de la superficie de la alfombra musiva que además indicará si ha habído movimientos o no, así como cualquier otro tipo de variación del estado del tapiz tras su exhumación en 2009 y su inmediata protección.

Esto resulta tremendamente relevante para este yacimiento y para otros que cuenten con suelos de estas características. Con la doble lectura del mismo pavimento se podrá testar el comportamiento de los mosaicos tras la retirada de la capa de tierra que los cubrían, pudiendo así programar de manera adecuada actuaciones preventivas tanto en éste como en otros tapicez musivos.

\subsection{Teledección}

En la actualidad, se estima que se ha excavado entre un 7 y un $10 \%$ de la totalidad de la superficie que ocupaba el complejo rural.

Para intentar avanzar en el conociento integral del complejo rural, en 2008 se realizó una prospección geofísica de una parte de la parcela donde se inserta el yacimiento. El objetivo era doble, por un lado avanzar en el conocimiento de la superficie ocupada por la villa, por otro lado, intentar discernir posibles trazas constructivas o de ocupación sectorial, de tal modo que estos datos ayudasen a planificar de manera coherente las ulteriores campañas de excavación, para intentar así optimizar los escasos recursos.

El principio de esta metología es bien conocido, basándose de manera sintética, en el análisis de los contrastes y variaciones de ciertos parámetros físicos característicos del suelo (como la conductividad eléctrica o la permeabilidad magnética) a partir de los cuales mediante un proceso de interpretación, se puede inferir la existencia o no de estructuras en el subsuelo.

Para este trabajo se empleó un equipo GEM-2 de Geophex, Ltd (Fig. 7).

De acuerdo con el método de trabajo establecido, en primer lugar se limpió de vegetación la zona a estudiar. Posteriormente se proyectaron sobre la superficie del terreno un total de 38 mallas rectangulares de $25 \times 30 \mathrm{~m}$ aproximadamente. Una vez marcados la totalidad de los ítems a analizar, el equipo técnico pasó el georradar en cada una de las cuadrículas, recorriéndolas en sucesivas batidas paralelas $y$ en dos direcciones perpendiculares entre sí, hasta rastrear la totalidad del 
espacio comprendido en cada una de los ajedrezados (Fig. 8). En total se analizó una superfie de $2 \mathrm{Ha}$.

La configuración del equipo hace que se tome una muestra cada $15 \mathrm{~cm}$, con frecuencias de $47875 \mathrm{~Hz}$, lo que proporcionó una información que alcanzaba los $2 \mathrm{~m}$ de potencia en algunos puntos.

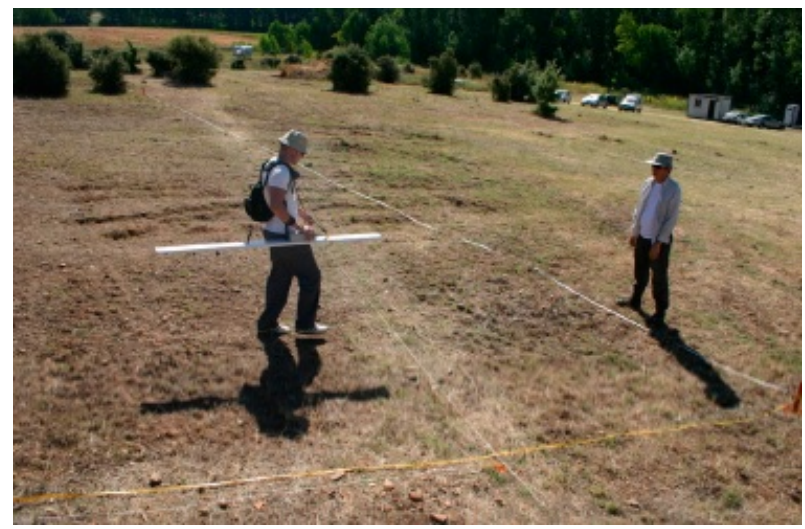

Figura 7: Equipo de trabajo.

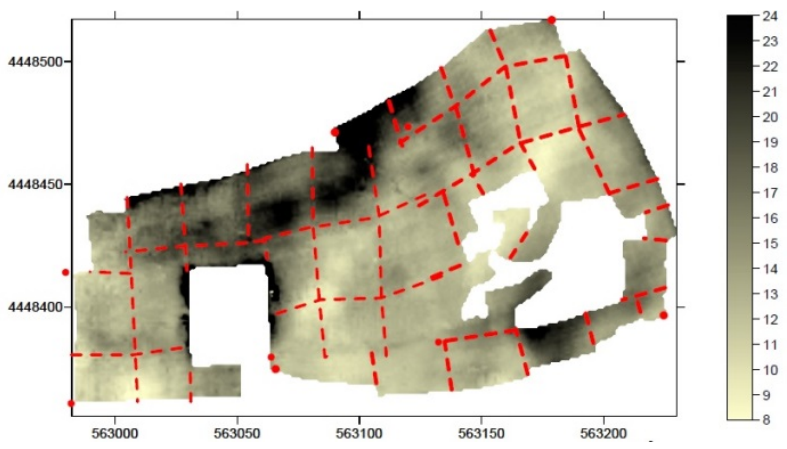

Figura 8: Aplicación del sistema de captación de datos en mallas equidistantes.

El resultado fue la documentación de una importante acumulación de alteraciones correspondientes a registros no geológicos, distinguiéndose patrones lineales de baja conductividad, junto a otros de alta correspondencia eléctrica.

Los datos tecnológicos indicaron algo que las posteriores campañas de excavación tuvieron la oportunidad de comprobar. La presencia de estructuras en posición yuxtapuesta y a diversas cotas, lo que permitía intuir varias fases de ocupación del yacimiento, con construcciones relevantes en cada una de las etapas cronoculturales.

Pese a que la capacidad técnica permitía abarcar un amplio espectro en profundidad (recordemos más de 2 m.), la lectura de los datos resultaba trementamente compleja, ya que sí en ocasiones ya es difícil descifrar testimonios sincrónicos ubicados a una cota similar, mucho más complicado resultaba discernir las referencias que se acumulaban en determinados puntos, presentando una extraordinaria acumulación de estructuras, muchas de ellas, como se ha indicado, yuxtapuestas.

Por este motivo, se optó obtener toda la información posible del yacimiento, pero solamente analizar las lecturas más superficiales de hasta $1 \mathrm{~m}$. de profundidad, dejando para una segunda etapa el estudio de los cortes que alcanzaron mayor calado.

Se obtuvo así un primer plano donde se indicaban las zonas de posibles acumulaciones de vertidos, las probables trazas de los muros, e incluso factibles pavimentaciones.

De este modo resultaba fácilmente identificable un posible trazado edilicio que podía corresponder a estructuras de grandes dimensiones ubicadas en el sector central. En los años posteriores se efectuaron algunos sondeos comprobatorios con resultados desiguales. Así, en determinados puntos sí se hallaron restos estructurales que tenía su correspondencia con la lectura efectuada por el georradar, mientras que en otros lugares, el análisis efectuado con los medios técnicos no tuvo su reflejo en los resultados obtenidos en la excavación arqueológica (Fig. 9).

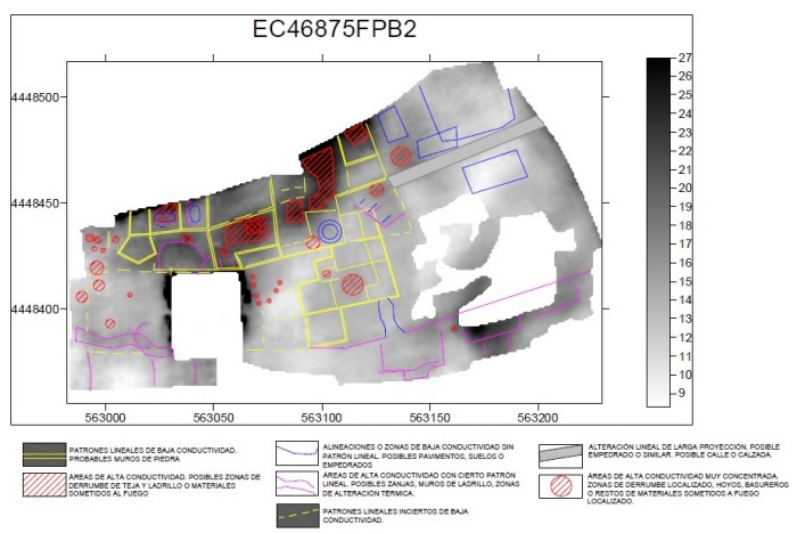

Figura 9: Interpretación arqueo-física de la zona.

El avance de las investigaciones arqueológicas en el yacimiento, aportará más información acerca de la eficiencia de los datos obtenidos mediante este sistema de prospección electromagnética.

\section{La atracción turística de la arqueología virtual: Noheda, el futuro del pasado}

El sector turístico en general y el arqueológico en particular, está constantemente sometido a un proceso de innovación, debido a que tiene que estar proporcionando emociones nuevas a los turistas ya que si no innovan los destinos se pueden convertir en rutinarios y dejan de ser visitados. Una manera de innovar ha sido ir adaptándose a las nuevas tecnologías.

En los últimos tiempos la utilización de estas nuevas tecnologías se ha convertido en un elemento necesario para cualquier destino turístico (Alles y Marqués 2014).

La innovación tecnológica que más ha avanzado ha sido la tecnología móvil, la cual ha teniendo una repercusión muy fuerte en la industria del turismo ya que permite obtener información en tiempo real de cualquier destino que se quiera visitar de manera muy sencilla. Realmente, los aparatos móviles, a través de distintos medios (posicionamiento, realidad aumentada, redes sociales, internet, etc.) han permitido facilitar esa conexión entre el turista y el el enclave histórico visitado (Imbert-Bouchard et al. 2013). 
Con el tiempo las nuevas tecnologías se han ido utilizando en todos los aspectos de nuestra vida, y en el caso de la arqueología no ha sido una excepción, ya que con ellas se ha tratado de representar yacimientos arqueológicos, edificios, objetos y de todo aquello que la mente de una persona pueda concebir.

Es interesante poder aprovechar todas las herramientas útiles que tenemos a nuestro alcance en internet (geoinformación, realidad aumentada, 3D, etc) para dar a conocer el rico patrimonio de un lugar. Éstas pueden llegar a ofrecen oportunidades para el desarrollo de estos destinos turísticos, como es el caso del yacimiento arqueológico de Noheda. Sin duda, pueden ser utilizas como una fuente de atracción turística.

Insertar este tipo de herramientas en el campo de la arqueología es lo que se denomina arqueología virtual. Su objetivo no solo es ayudar a los científicos a la demostración de sus hipótesis arqueológicas, sino también difundir los yacimientos mediante su reconstrucción para una fácil comprensión y siempre teniendo en cuenta la adaptación de los mismos a cualquier tipo de visitante. El empleo de estas tecnologías podrá llegar a fomentar el turismo arqueológico de la villa romana de Noheda ya que con estas herramientas se puede apoyar a su difusión turística, como una forma de poder conocer y recorrer este enclave mediante un recorrido virtual.

Unas de las herramientas tecnológicas más importantes que se podrían ofrecer en este excepcional yacimiento es la realidad aumentada. A pesar de que es un concepto que se ha venido manejando en los últimos años, en investigación teórica ya se hacía desde los años 60 del siglo XX (Wei et al. 2014).

La realidad aumentada es una tecnología que trata de unir el entorno real con un entorno virtual, basándose en la sobreimpresión de elementos virtuales en la realidad a tiempo real (Callejas et al. 2011). Esto, aplicado para este yacimiento, se puede conseguir a través de una aplicación móvil (App) que le va a permitir una diferenciación a nivel de otros destinos arqueológicos.

Para cualquier persona no especialista en arqueología, a veces resulta excesivamente complicado poder entender un yacimiento observando solamente los restos encontrados o expuestos. Para evitarlo, una buena opción será esa recreación virtual tanto del yacimiento, a través de la realidad aumentada como la herramienta del modelado 3D de piezas (sobre todo esculturas) que se van encontrando en determinados puntos del enclave y que el visitante podrá observar simplemente leyendo los códigos bidimensionales o QR con sus dispositivos móviles o tablets. Estos códigos serán colocados en el punto donde se encontraban las piezas en el momento de uso de la villa.

La utilización de esta otra herramienta del 3D en el yacimiento se puede realizar con un doble objetivo, por un lado, para generar la visión conexa de los fragmentos reales y por otro lado, la integración de éstos dentro de la reconstrucción, siempre diferenciándose los restos originales, de los que no lo son. Será una manera para visualizar las dos propuestas de un solo vistazo (GarcíaMorales et al. 2015).

Este uso virtual, que en los últimos tiempos se desarrolla en el campo de la arqueología está teniendo un gran éxito. La posibilidad y capacidad de la representación virtual de de Noheda facilitará el entendimiento de éste, para cualquier público, añadiéndole siempre un especial atractivo. Esto puede ayudar a conseguir que la sociedad muestre interés por su propio patrimonio, especialmente por su puesta valor, pues difícilmente se puede proteger algo si se desconoce. También esta tecnología nos ayudaría a que en caso de pérdida o mala conservación sepamos cómo era inicialmente.

Pero sin duda, la incorporación de estas nuevas tecnologías en arqueología la villa romana de Noheda, no solo contribuirá al trabajo de los arqueólogos sino que también será una medida de atracción turística que ayudará a la difusión y protección del patrimonio cultural.

\section{Conclusiones}

Un yacimiento arqueológico de la relevancia de Noheda, en el cual se hallan uno de los mosaicos figurativos más destacados del imperio romano, está llamado a ser un acicate en la revitalización turística de la zona. Pero para que un enclave pueda ser adecuadamente difundido, valorado y enseñado, es necesario la aplicación de una correcta metodología arqueológica que ayude a interpretar correctamente el sitio. En esta línea, no solo se han de tener en cuenta las tradicionales técnicas de excavación arqueológica, sino también el empleo de las nuevas tecnologías como elemento que ayudan a planificar y enterner los procesos arqueológicos, así como para utilizarlos en la musealización de la villa.

De este modo, en Noheda, tal y como se ha expuesto, desde hace años ya se están usando toda una serie de métodos no intrusivos de investigación arqueológica. Pero esto no es sino un primer paso en el empleo de estas nuevas tecnologías que serán aplicadas con profusión de cara a conocer y difundir de manera adecuada el enclave.

\section{Agradecimientos}

Este artículo se ha elaborado en el marco del proyecto Conservación preventiva de los mosaicos romanos de la villa romana de Noheda (Cuenca), del lugar arqueológico de I'Almoina (Valencia) y otros HAR 201347895-C2-1-P, dirigido por F. García-Diego. Por otro lado, algunos de los estudios enumerados en este trabajo fueron sufragados gracias a los proyectos de investigación: Estudio integral del triclinium $y$ dependencias anejas de la villa romana de Noheda 14.546 y Estudio estratigráfico del sector residencial de la villa romana de Noheda 15.0923, dirigidos por Miguel Ángel Valero Tévar.

Además el desarrollo de las excavaciones se ha efectuado gracias a la financiación de la Junta de Comunidades de Castilla-la Mancha, la Excma. Diputación de Cuenca y la colaboración del Excmo Ayuntamiento de Villar de Domingo García. 


\section{Referencias}

ABASCAL, J.M., 1982. Vías de Comunicación romanas de la provincia de Guadalajara, Ed. Diputación Provincial de Guadalajara. Instituto Provincial de Cultura "Marqués de Santillana”, Guadalajara.

ALLES, M.T.F., y MARQUÉS, R.C., 2014. El impacto de las nuevas tecnologías en el sector turístico: aplicación de la realidad aumentada al turismo cultural, en Cultura, desarrollo y nuevas tecnologías: VII Jornadas de Investigación en Turismo, Sevilla, 11 y 12 de Junio de 2014, pp. 317-333.

ARCE, J., 2006. Villae en el paisaje rural de Hispania romana durante la Antigüedad tardía, en CHAVARRÍA, A., ARCE, J. y BROGIOLO, G.P. eds., Villas Tardoantiguas en el Mediterráneo Occidental, Anejos de AEspA XXXIX, Madrid, pp. 9-15.

ARCE, J., 2009. El último siglo de la España romana, 284-412, Madrid.

ARCE, J., 2010. El complejo residencial tardorromano de Cercadilla, (Corduba), En VAQUERIZO, D., ed., Las áreas suburbanas en la ciudad histórica. Topografía, usos, función, Monografías de Arqueología Cordobesa, 18, pp. 397412.

ARCE, J., 2012. Campos, tierras y villae en Hispania, En CABALLERO, L., MATEOS, P. y CORDERO, T. eds., Visigodos y Omeyas. El territorio, Mérida, pp. 21-30.

BALMELLE, C., 2001. Les demeures aristocrutiques d'Aquitaine, Ausonius-Aquitania, Supplément, 10, Bordeaux-Paris.

BEZZI, A., 2013. Caldonazzo castle - from ruins to archaeological 3D reconstruction, ATOR (Arc-Team Open Research), 9 de diciembre de 2013 DOI: http://arc-team-open-research.blogspot.com.es/2013/12/caldonazzo-castle-from-ruinsto.html [Consulta: 23-02-2016].

CALLEJAS, M., QUIROGA, J.G. y ALARCÓN, A.C., 2011. Ambiente interactivo para visualizar sitios turísticos, mediante realidad aumentada implementando Layar, Ciencia y Tecnología Neogranadina, 21-2, pp. 91-105.

CHAVARRÍA, A., 2005. Villas in Hispania during the fourth and fifth Centuries, En BOWES, K. y KULIKOWSKI, M. eds., Hispania Late Antiquity. Current Perspectives, Leiden-Boston, pp. 518-555.

CHAVARRÍA, A., 2006: Villas en Hispania durante la Antigüedad tardía, En CHAVARRÍA, A., ARCE, J. y BROGIOLO, G.P. (eds.), Villas Tardoantiguas en el Mediterráneo Occidental, Anejos de AEspa XXXIX, Madrid, pp. 17-35.

CHAVARRÍA, A., 2007. El final de las uillae en Hispania (siglos IV-VIII), BAT 7, Brepols, Turnhout.

DE REU, J., Plets, G., VerhoeVEN, G., DE SMEDT, P., BATS, M., CheRRetTe, B., DE MAEYER, W., DECONYNCK, J., HERREMANS, D., LALOO, P. y VAN MEIRVENNE, M., 2013. Towards a three-dimensional costeffective registration of the archaeological heritage, Journal of Archaeological Science, 40, pp. 1108-1121. DOI: http://www.journals.elsevier.com/journal-of-archaeological-science/ [Consulta: 27-2-2016]

DONEUS, M., VERHOEVEN, G., FERA, M., BRIESE, C., KUCERA, M. y NEUBAUER, W., 2011. From deposit to point cloud e a study of low-cost computer vision approaches for the straightforward documentation of archaeological excavations, En CEPEK, A. ed., XXIII International CIPA Symposium, Prague, 12-16 September 2011, Geoinformatics, Vol. 6, Prague: Faculty of Civil Enginnering, Czech Technical University, pp. 81-88. DOI: http://pubgeo.tuwien.ac.at/showentry.php?ID=206899/=6\&nohtml=1. [Consulta:15-2-2016].

DUNBABIN, K.M.D., 2003. The Roman Banquet. Images of conviviality, Cambridge University Press, Cambrige.

GARCÍA-ENTERO, V., 2005. Los balnea domésticos -ámbito rural y urbano- en la Hispania romana, Anejos de Archivo Español de Arqueología, XXXVII, Madrid.

GARCÍA-ENTERO, V., 2006. Los balnea de las villae tardoantiguas en Hispania, Anejos de Archivo Español de Arqueología, XXXIX, pp. 97-111.

GARCÍA-MORALES, R.M., CORTINA, M.L., PINTADO, J.A., y NOVELLA, L.R., 2015. Princeps Resurgens: investigación arqueológica y documentación fotogramétrica en el estudio de una estatua romana thoracata de Los Bañales (Uncastillo, Zaragoza), Virtual Archaeology Review, 6(13), pp. 65-71. DOI: http://dx.doi.org/10.4995/var.2015.4379 [Consulta: 29-02-2016].

GROS, P., 2001. L'Architecture romaine, 2. Maisons, palais, villas et tombeaux, París.

HIDALGO, R., 1998. El triclinium triconque del palatium de Córdoba, Anales de Arqueología Cordobesa, 9, pp. 273-300.

HIDALGO, R., 2014. ¿Fue Cercadilla una villa? El problema de la función del complejo de Cercadilla en Corduba, Archivo Español de Arqueología, 87, pp. 217-241.

IMBERT-BOUCHARD, D., LLONCH, N., MARTIN, C. y OSÁCAR, E., 2013. Turismo cultural y apps. Un buen panorma de la situación actual, HER\&MUS, 2, sept-oct, pp. 44-54.

JANCOSEK, M. y PAJDLA, T., 2011. Multi-View Reconstruction PreservingWeakly-Supported Surfaces, CVPR, pp. 3121-3128. DOI: http://dx.doi.org/10.1109/cvpr.2011.5995693 [Consulta: 29-02-2016]. 
JOHNSTON, D.E., 1983. Roman Villas, Aylesbury Shire.

LARRAÑAGA, J., 1966. Guía de Cuenca, Cuenca: Excma. Diputación Provincial de Cuenca.

LLEDÓ, J.L., 2007. El Mosaico de Noheda (Cuenca): Su descubrimiento, Cuenca: Ed. Excma. Diputación Provincial de Cuenca.

LLEDÓ, J.L., 2010. El Mosaico Romano de Noheda: Historia personal de un alumbramiento, Madrid: Ed. Visión Libros.

MAÑANA-BORRAZÁS, P, RODRÍGUEZ, A. y BLANCO-ROTEA, R., 2008. Una experiencia en la aplicación del Láser Escáner a los procesos de documentación y análisis del Patrimonio Construido: su aplicación a Santa Eulalia de Bóveda (Lugo) y San Fiz de Solovio (Santiago de Compostela, Arqueología de la Arquitectura, 5, pp. 15-32.

MAR, R. y VERDE, G., 2008. Las villas tardoantiguas: cuestiones de tipología arquitectónica, En FERNÁNDEZ, C.; GARCÍA, V. y GIL, F. eds., Las villae tardorromanas en el occidente del imperio: Arquitectura y Función. Gijón: Ed. Trea, pp. 50-83.

MARTÍNEZ, C., MEJÍAS, M., GOICOECHEA, P.P. y VALERO, M.A., 2014. Posibilidades de abastecimiento subterráneas de la villa romana de Noheda y características geológicas de su entorno, Cuenca: IGME-Excma. Diputación Provincial de Cuenca.

McCARTHY, J., 2014. Multi-image photogrammetry as a practical tool for cultural heritage survey and community engagement Journal of Archaeological Science, 43, pp. 175-185. DOI:10.1016/j.jas.2014.01.010

McKAY, A.G., 1975. Houses, Villas and Palaces in the Roman World, London.

MEJÍAS, M., MARTíNEZ, C., GOICOECHEA, P.P. y VALERO, M.A., 2013. Estudio Geológico e Hidrológico del yacimiento arqueológico de Noheda (Villar de Domingo García, Cuenca), Instituto Geológico y Minero de España, IGME.

MULVIN, L., 2002. Late Roman Villas in the Danube-Balkan Region, Oxford: BAR Int. Ser. 1064.

PALOMERO, S., 1987. Las vías romanas de la provincia de Cuenca, Cuenca: Excma. Diputación Provincial de Cuenca.

PENSABENE, P., 2010-2011. La villa del Casale tra Tardo Antico e Medioevo alla luce dei nuovi date archaeologici: funcioni, decorazioni e transformazioni, Rendiconti della Pontificia Accademia Romana di Archeologia, LXXXIII, pp. 141-226.

PERCIVAL, J., 1976. The Roman Villa, A Historical Introduction, London.

POIRIER, N., HAUTEFEUILLE, F. y CALASTRENC, C., 2014. Utilisation des micro-drônes pour la prospection archéologique à basse altitude, Colloque scientifique francophone. Drones et moyens légers aéroportés d'observation. Montpellier, 24-26 Juin 2014. DOI: http://drone.teledetection.fr/restitue.php [Consulta: 29-02-2016].

RICHMOND, I., 1970. The plans of roman villas in Britain, En RIVET, A.L.F. ed., The Roman Villas in Britain, London, pp. 49-70.

RODÀ, I., 2004. El mármol como soporte privilegiado en los programas ornamentales de época imperial, En RAMALLO, S. ed., La decoración arquitectónica en las ciudades romanas de Occidente. Actas del Congreso Internacional celebrado en Cartagena entre los días 8 y 10 de octubre de 2003. Murcia: Universidad de Murcia, pp. 405-420.

ROMIZZI, L., 2006. Le ville tardo-antiche in Italia, En CHAVARRÍA, A., ARCE, J. y BROGIOLO, G.P. eds., Villas Tardoantiguas en el Mediterráneo Occidental, Anejos del Archivo Español de Arqueología, 39, pp. 37-59.

ROSSITER, J., 1991: "Convivium and Villa in Late Antiquity", En SLATER, W. J. (ed.), Dinning in a classical Context, Michigan, pp. 199-214.

RUIZ, J.A., GALLEGO, D., PEÑA, C., MOLERO, J.M. y GÓMEZ, A., 2015. Fotogrametría aérea por drone en yacimientos con grandes estructuras. Propuesta metodológica y aplicación práctica en los castillos medievales del Campo de Montiel, Virtual Archaeology Review, 6(13), pp. 5-19. DOI: http://dx.doi.org/10.4995/var.2015.4366 [Consulta: 29-02-2016].

SHAN, Q., WU, Ch., CURLESS, B., FURUKAWA, Y., HERNÁNDEZ, C. y SEITZ, S.M., 2014. Accurate Geo-registration by Ground-to-Aerial Image Matching, International Conference on 3D Vision 2014. Tokyo.

SFAMENI, C., 2006. Ville residenziali nell'Italia Tardoantica, Edipuglia, Bari.

VALERO, M.A., 1999a. La Necrópolis tumular de la Punta del Barrionuevo. Iniesta-Cuenca, En VALERO, M.A., ed., Actas de las $1^{a}$ s Jornadas de Arqueología Ibérica en Castilla-La Mancha. Toledo: Serie Patrimonio Histórico, pp. $181-200$

VALERO, M.A., 1999b: El Origen del Mundo Celtibérico en la Meseta Sur, Actas de I Encuentros sobre el Mundo Celtibérico. Guadalajara, pp. 213- 219.

VALERO, M.A., 2008. El territorio Ibérico en La Manchuela: avance de los primeros resultados, Studia académica, Número extraordinario 1, pp. 155-195.

VALERO, M.A., 2009. La villa de Noheda: esplendor tardoimperial, Revista Memorias, 15, pp. 53-58. 
VALERO, M.A., 2010. La villa romana de Noheda: Avance de los primeros resultados, Informes sobre Patrimonio 1, http://informes.patrimoniohistoricoclm.es/2010-03/patrimonio.html. [2/15/ 2016].

VALERO, M.A., 2011. Les images de ludi de la mosaïque romaine de Noheda (Villar de Domingo García, Cuenca), Nikephoros, 24, pp.91-114.

VALERO, M.A., 2013a. The late-antique villa at Noheda (Villar de Domingo García) near Cuenca and its mosaics, Journal of Roman Achaeology, 26, pp. 307-330.

VALERO, M.A., 2013b. El cambio de patrón poblacional en el territorium de Ercávica: Avance sobre un proyecto de evolución del paisaje en La Alcarria, en CERDEÑO, Ma.L., SAGARDOY, T. y GAMO, E. eds., La Romanización en la provincia de Guadalajara. Guadalajara: La Ergástula, pp. 221-236.

VALERO, M.A., 2014a. El triclinium de la villa de Noheda (Villar de Domingo García. Cuenca), En PENSABENE, P. y SFAMENI, C., eds., La Villa Restaurata e i Nuovi Studi sull'Edilizia Residenziale Tardoantica. Bari: Edipuglia, pp. $521-531$.

VALERO, M.A., 2014b. Estudio arqueométrico de las muestras procedentes del mosaico de la villa romana de Noheda (Cuenca): primeros resultados, Actas del X Congreso Ibérico de Arqueometría, Castellón: Instituto de Conservación y Restauración Valenciano, pp. 54-68.

VALERO, M.A., 2014c. La representación de instrumentos musicales en el mosaico de la villa romana de Noheda, Libro de la 53 SMR de Cuenca, Cuenca: Excma. Diputación de Cuenca, pp. 81-104.

VALERO, M.A., 2015a. La villa romana de Noheda: la sala triclinar y sus mosaicos. Tesis Doctoral, Universidad de Castilla-La Mancha.

VALERO, M.A., 2015b. Los mosaicos del triclinium de la villa romana de Noheda (Villar de Domingo García, Cuenca), En ÁlVAREZ, J.M., NOGALES, T. y RODÀ, I. eds., Proceedings XVIIITH International Congress of Classical Archaeology. Mérida: Museo Nacional de Arte Romano, pp. 1347-1351.

VALERO, M.A., e.p.: El territorium de la villa romana de Noheda, Cuenca, En SANZ, R. y CARNEIRO, A., Actas del I Congresso Internacional sobre Arqueologia de Transição: "Entre o Mundo Romano e a Idade Média", Évora: Universidad de Évora.

VALERO, M.A. y GÓMEZ, J., 2013. El mimo celoso adinerado: literatura y espectáculo en la uilla romana de Noheda, Quaderni Urbinati de Cultura Classica, 102, pp. 87-106.

VALERO, M.A., MERELLO, P., FERNÁNDEZ, A., y GARCíA-DIEGO, F.J., 2014. Characterisation and evaluation of a thermo-hygrometric corrective action carried out at the Noheda archaeological site (Noheda, Spain), Sensors, 14, pp. 1665-1679.

VALERO, M.A., GUTIÉRREZ, A. y RODÀ, I, 2015. First preliminary results on the marmora of the late roman villa of Noheda (Cuenca, Spain), En PENSABENE, P. y GASPARINI, M. eds., Interdisciplinary Studies on Ancient Stone. ASMOSIA X. Roma: L'Erma di Bretscheider, pp. 359-380.

VERA, D., 1992-1993. Schiavitù rurale e colonato nell'Italia imperiale, Scienze dell'Anchiquità Storia Archaeologica Antropógica, 6-7, pp. 291-339.

VOLPE, G., 1996. Contadini, pastori e mercanti nell'Apulia tardoantica, Munera 6, Bari.

VOLPE, G., 2006. "Stibadium e convivium in una villa tardoantica (Faragola-Ascoli-Satriano)", en SILVESTRINI, M., SPAGNUOLO VIGORITA, T. y VOLPE, G. (eds.), Studi in onore di Francesco Grelle, Bari, p. 319-349.

WEI, S., RENI G. y O'NEILL, E., 2014. Haptic and Audio Displays for Augmented Reality Tourism Applications, IEEE Haptics Symposium 2014, pp. 485-488. DOI: 10.1109/HAPTICS.2014.6775503 [Consulta: 29-02-2016].

WESTOBY, M.J., BRASINGTON, J., CLASSER, N.F., HAMBREY, M.J. y REYNOLDS, J.M., 2012. "Structure-fromMotion photogrammetry: A low-cost, effective tool for geoscience applications, Geomorphology, 179, pp. 300-314. DOI:10.1016/j.geomorph.2012.08.021 [Consulta: 29-02-2016].

WU, Ch., 2013. Towards Linear-time Incremental Structure from Motion, International Conference on 3D Vision 2013. Seattle. DOI: 10.1109/3DV.2013.25 [Consulta: 29-02-2016]. 